TRABAJOS DE PREHISTORIA

54, n. ${ }^{\circ} 2,1997$, pp. $61-80$

\title{
DE LA ARQUEOLOGÍA \\ SIMBÓLICA DEL PAISAJE \\ A LA ARQUEOLOGÍA \\ DE LOS PAISAJES \\ SAGRADOS
}

\author{
FROM A LANDSCAPE SYMBOLIC \\ ARCHAEOLOGY TO AN \\ ARCHAEOLOGY OF SACRED \\ LANDSCAPES
}

\section{MANUEL SANTOS ESTÉVEZ (*) \\ CÉSAR PARCERO OUBIÑA $(*)$ \\ FELIPE CRIADO BOADO (*)}

Anda, quítate el vestido,

las flores y las trampas.

[L.E. AutE, Anda]

\section{RESUMEN}

Se estudian los diferentes modelos de paisaje que se suceden en la Prehistoria e Historia de una comarca del noroeste de la Península Ibérica. Se analizan tanto la distribución del poblamiento y el uso del suelo a la luz de datos geográficos y arqueológicos, como la articulación de organizaciones territoriales supralocales. En concreto se observa la conformación de un espacio simbólico o sagrado en un sector concreto de la zona de estudio que habría servido como recurso fundamental para configurar y expresar los modelos de paisaje social de cada momento. Con ello se pretenden mostrar las diferentes formas de racionalidad que se esconden detrás de la concepción de lo sagrado a lo largo de varias etapas culturales distintas y sucesivas; se trata de mostrar lo que cada una de estas fases ha aportado a la construcción acumulativa del paisaje que se observa actualmente y de descifrar para cada una de ellas una concepción del paisaje diferente. La zona de estudio se encuadra dentro del área nuclear de los petro-

(*) Grupo de Investigación en Arqueología del Paisaje, Universidade de Santiago de Compostela. Laboratorio de Arqueología, Edificio «Monte da Condesa», Campus Sur, Santiago (A Coruña=.pharpa@usc.es).

El artículo fue remitido en su versión final el 17-VII-97. glifos galaicos de la Edad del Bronce, entre los ayuntamientos de Campo Lameiro y Cotobade (Pontevedra). Creemos que en ella se conservan elementos de su valor simbólico desde la Edad del Bronce hasta la Galicia tradicional. Lejos de proponer ningún tipo de persistencias seculares, nuestro análisis tratará de mostrar cómo cada uno de estos hitos se construye a partir de una concepción diferente del paisaje y cómo todas ellas, pese a esto, coinciden en remarcar una zona dotada de peculiares condiciones naturales, diferentemente interpretadas en cada momento.

\begin{abstract}
This paper deals with the different models of landscapes found in the Prehistory and History of the northwest area of the Iberian Peninsula. We consider both the pattern of settlement and land-use and the arrangement of supralocal territorial units. This study particularly focuses on the form of a symbolic or sacred landscape in a specific part of our research area. This sacred landscape would have represented the models of social landscapes in each
\end{abstract}


period. By these means, we try to show the different patter$n s$ of rationality that lie behind the conception of sacred through some distinctive cultural periods; the aim is to show the contribution of each period for the cumulative construction of the present day landscape and to decode a different conception of landscape for each phase. The analysis has been made for a single zone within the core area of Galician Bronze Age rock art, between Campo Lameiro and Cotobade municipalities (Pontevedra). We think we have discovered elements of that symbolic meaning in the Bronze Age, the Iron Age, the Roman period, the early Middle Ages and the Galician traditional rural world. Far away from the proposal of secular survivals, our analysis try to show how each one of those land marks is built up from a specific conception of landscape, although all of them coincide in marking an area endowed with peculiar natural conditions, but given different interpretations in each period.

Palabras clave: Arqueología del Paisaje. Arqueología Rural. Espacio social. Espacio simbólico. Territorialidad. Petroglifos. Edad del Bronce. Cultura castreña. Romanización. Geografía Rural.

Keywords: Landscape Archaeology. Rural Archaeology. Social space. Symbolic space. Territoriality. Rock art. Bronze Age. Castros culture. Romanization. Rural Geography.

\section{DESCRIPCIÓN, FORMA, DECONSTRUCCIÓN, SENTIDO (PLANTEAMIENTO)}

Se pretende reconstruir la secuencia de paisajes arqueológicos que se han sucedido en una zona de Galicia entre el IV milenio a.C. y la Edad Media. El interés fundamental de este trabajo no es sólo ofrecer esa síntesis diacrónica, sino mostrar que, a partir de un cierto momento, uno de los principios básicos de organización del paisaje social en la zona podría haber sido la constitución de un cierto tipo de espacio sagrado. Esta dimensión no habría excluido otras funcionalidades, incluso de carácter práctico-cotidiano, sino que se debe entender como la significación de la zona dentro de un código de lectura de carácter simbólico-ideológico.

La estrategia de investigación que aplicamos se basa en opciones teóricas bien definidas e intenta articular el análisis de los paisajes arqueológicos como una práctica deconstructiva que pretende reconstruir el objeto de estudio de acuerdo con sus propias normas y sin introducir un sentido ajeno a él. Teniendo en cuenta que el paisaje, como todo producto humano, es la objetivación de una intención, sentido y racionalidad previa que se actualizan en elementos formales concretos y que, como tal, esos elementos deben representar de algún modo (siquiera sea distante) los contornos de aquella racionalidad, se propone desarrollar una descripción del paisaje que deconstruya éste y permita aislar los elementos y relaciones formales que lo constituyen. El sentido se debería desprender de esas formas y relaciones, imponer por el peso de su propia materialidad, y no debería referirse a un horizonte de inteligibilidad ajeno a él.

Este proyecto, que intenta realizar, en la parcial medida en que es posible en Arqueología, un análisis estructural del significante (1), encuentra los instrumentos adecuados en la redefinición de las nociones de descripción, deconstrucción y análisis formal.

- Entendemos descripción en el sentido que le otorga Feyerabend (1974: 118) quien establece que "hay sólo una tarea que podamos legítimamente pedir a una teoría, y es que nos dé una descripción correcta del mundo, es decir, de la totalidad de los hechos vistos a través de sus propios conceptos".

- Con el concepto deconstrucción nos referimos a dos cosas distintas a la vez: a una metodología y a una crítica. Por un lado a una práctica analítica que accede al sentido de una determinada construcción social no reconstruyéndolo, sino destruyéndola; de-construir es extraer los niveles que constituyen una realidad para descubrir su morfología y configuración interna; en la re-construcción por adición (es lo que se pone); en la deconstrucción el sentido se genera por sustracción (es lo que queda). Por otro, en el sentido que Derrida (1989) otorga al término, la deconstrucción es una práctica que desenmascara las relaciones entre los conceptos fundamentales de la racionalidad moderna y evidencia de qué modo en nuestro saber se reconstruye siempre el mismo modelo de subjetividad (o logocentrismo). Por lo tanto, plantear una deconstrucción del paisaje supone al mis-

(1) Propuesta enunciada por Foucault (1976) en el prefacio de La historia de la locura y con la que pretendía inaugurar una metodología de análisis de los productos sociales que escapara a la subjetividad de la interpretación. En nuestro caso los 'significantes' serían los elementos descarnados del registro arqueológico desprovistos de sentido subjetivo.

T. P., 54, n. $^{\circ} 2,1997$ 
mo tiempo descomponer el espacio social prehistórico para estudiarlo, y evitar que el estudio reproduzca los rasgos del horizonte de racionalidad del estudioso.

- Entendemos por análisis formal o morfológico el análisis de las formas materiales concretas que constituyen el paisaje, tanto las naturales (geográficas) como las artificiales (elementos de Cultura Material, monumentos ...), sin introducir un sentido extraño a ellos. Es por tanto un tipo de práctica deconstructiva que, cuando tiene éxito, describe el objeto de estudio desde dentro de sí mismo.

El proceso metodológico que se seguirá es el habitual en el análisis antropológico estructural. Consiste en contraponer los modelos formales de organización del espacio desprendidos del estudio de diferentes tipos de espacios arqueológicos. Las etapas de trabajo se pueden esquematizar de la siguiente forma.

1. Empezamos por realizar un análisis formal del espacio físico y de los espacios arqueológicos existentes en la zona. Estos últimos se representan, entre otros, en el patrón de distribución y emplazamiento de los yacimientos arqueológicos de cada periodo. El estudio del espacio físico, por su parte, incluye tanto el análisis de su morfología como de los patrones de poblamiento y uso del suelo tradicionales; éstos aportan una analogía débil que permite resaltar qué es relevante en el espacio considerado. El estudio de esos espacios debe conducir a la definición de un modelo hipotético concreto sobre la organización formal de cada uno.

2. Una vez desprendidos los esquemas formales de cada espacio considerado, analizando códigos espaciales distintos pertenecientes a cada contexto cultural (por ejemplo: el emplazamiento de petroglifos comparado con el esquema espacial de sus composiciones, con las formas de uso del suelo, organización del espacio doméstico y dinámicas sociales del periodo, etc.), podremos generalizar el modelo concreto para poder establecer el modelo hipotético ideal.

3. La coherencia de este modelo se puede contrastar considerando en detalle otros ámbitos y niveles de cada contexto para comprobar si en ellos reaparece el mismo modelo ideal o, en todo caso, transformaciones de éste. Esto supone en definitiva observar si en niveles diferentes de la misma cultura se evidencian los mismos códigos de organización espacial que se aprecian en el primer nivel. Así podremos definir el modelo genérico ideal.

4. Una vez desprendidos los modelos característicos de cada fase o regularidad espacial, se comparan unos con otros con el fin de examinar las conjunciones y disyunciones más notables. El principio orientador de esta fase del análisis es que las correspondencias entre códigos espaciales de contextos culturales que no tienen nada que ver entre sí no son debidas a una identidad o continuidad cultural, sino el resultado de principios de organización semejantes, los más obvios de los cuales están contenidos o determinados por la propia organización del espacio físico.

Por su parte, la definición de cada modelo formal de organización espacial se puede realizar mediante un análisis cuyas principales fases son:

1. reconocimiento de las formas o constituyentes elementales del espacio considerado, tanto naturales (es lo que tradicionalmente se denominaría un análisis fisiográfico) como artificiales o arqueológicos;

2. caracterización de las condiciones de visibilidad y visibilización de esas formas;

3. identificación de la red de lugares significativos de ese espacio, esto es: aquellas formas individuales que se definen por características específicas (visibilidad entre otras) y que pueden funcionar de hecho como puntos básicos de organización del espacio circundante;

4. identificación de las claves de tránsito y desplazamiento que hacen permeable ese espacio y preestablecen el sentido de los movimientos sobre él;

5. definición de las cuencas visuales o panorámicas más significativas de la zona, tanto las topográficas como las constituidas en torno a las entidades arqueológicas;

6. definición de las cuencas de ocupación, esto es: las zonas más adecuadas para el asentamiento humano que constituyen auténticos lugares (en el sentido gallego del término: aldea vinculada a un espacio fijo y delimitado) pero que en vez de ser meros puntos son zonas más amplias y generalmente se corresponden con cubetas o valles;

7. reconstrucción de la jerarquía de lugares que se deriva de la accesibilidad o permeabilidad diferencial de cada una de las formas, lugares y cuencas existentes en ese espacio. 


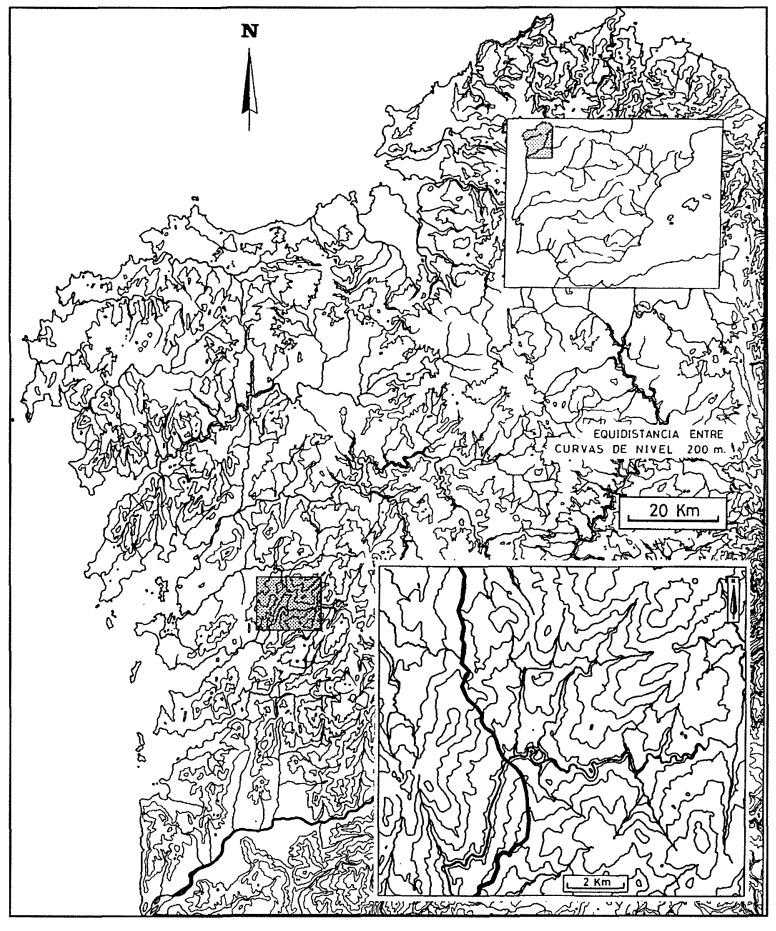

Fig. 1. Localización de la zona de trabajo, con el trazado del oleoducto Coruña-Vigo.

\section{LAS FORMAS DEL ESPACIO (DATOS)}

\subsection{La posibilidad}

Para desarrollar nuestro trabajo hemos elegido una zona ubicada en el centro de la provincia de Pontevedra, en la franja occidental de Galicia (Fig. 1). Se trata de un área de aproximadamente de $130 \mathrm{~km}^{2}$ que comprende la práctica totalidad del término municipal de Campo Lameiro y la mitad Norte del de Cotobade, que conforma una unidad geográfica bien definida y de la que se dispone de un abundante corpus de datos.

La convergencia de investigaciones en esta zona se debe a la gran densidad y riqueza de grabados rupestres que aquí se concentran y que conforman uno de los conjuntos más impresionantes de Galicia, de tal modo que casi todas las publicaciones existentes se relacionan de una u otra forma con estos grabados rupestres.

Las primeras investigaciones importantes corrieron a cargo de arqueólogos vinculados al Museo de Pontevedra, con A. García Alén a la cabeza (García Alén y Peña Santos, 1980) y fueron conti- nuadas por A. Álvarez (1979) y A. de la Peña $e t$ alii (1993), concentrándose de forma mayoritaria en los grabados rupestres, y secundariamente en uno de los yacimientos castreños de la zona, el Castro de Penalba (Álvarez, 1986).

Más recientemente fue una de las zonas elegidas por el equipo formado por Bradley, Criado y Fábregas (1994a, b, 1995) para estudiar el emplazamiento de los petroglifos dentro de un proyecto de trabajo que pretendía revisar este fenómeno desde la perspectiva de la Arqueología del Paisaje.

En el año 1993 la zona es atravesada por el Oleoducto Coruña-Vigo, construido por la Empresa CLH, cuyo proyecto de Evaluación y Corrección de Impacto Arqueológico tuvo ocasión de realizar nuestro Equipo de Trabajo (Fig. 1). La participación de un equipo arqueológico en todas las fases de este proyecto implicó la realización de una completa serie de trabajos que van desde la prospección superficial para informar el Impacto Arqueológico del trazado (trabajo dirigido por F. Méndez en 1992, Méndez et alii, 1995) al seguimiento de la construcción (realizado en 1993, Criado et alii, 1995). Todo ello supuso una notable profundización en el conocimiento de la zona, especialmente en el sentido de atender a la totalidad del registro arqueológico, incluyendo la inspección del subsuelo en toda la longitud de la traza del Oleoducto, ya que el área de estudio fue inspeccionada por sucesivos equipos de campo entre 1992 y 1995. Los trabajos incluyeron la definición y sondeo de yacimientos habitacionales del Neolítico y Edad del Bronce descubiertos gracias a las obras (Criado et alii, 1996), el estudio de la Cultura Material recuperada (Cobas y Prieto, e.p.), el estudio de la distribución de monumentos tumulares (Villoch, 1995), y la identificación de estructuras anejas a castros (Criado y Parcero, e.p.).

Ante el interés de los datos obtenidos, se propuso ampliar el trabajo en dos direcciones: intensificando el estudio de la distribución y emplazamiento de petroglifos (trabajo realizado en 1996 por M. Santos) (2); y profundizando en el análisis del poblamiento durante la Edad del Hierro (realizado en 1996 por C. Parcero). Uniendo a ello los resultados del trabajo de catalogación arqueológi-

(2) Aprovechando, en algún caso, actuaciones de tipo patrimonial como el control de la reforestación en los montes comunales de Parada, trabajo realizado por uno de los autores (MSE) en colaboración con M. Alfonsín Soliño y encargado por la Consellería de Cultura de la Xunta de Galicia. 


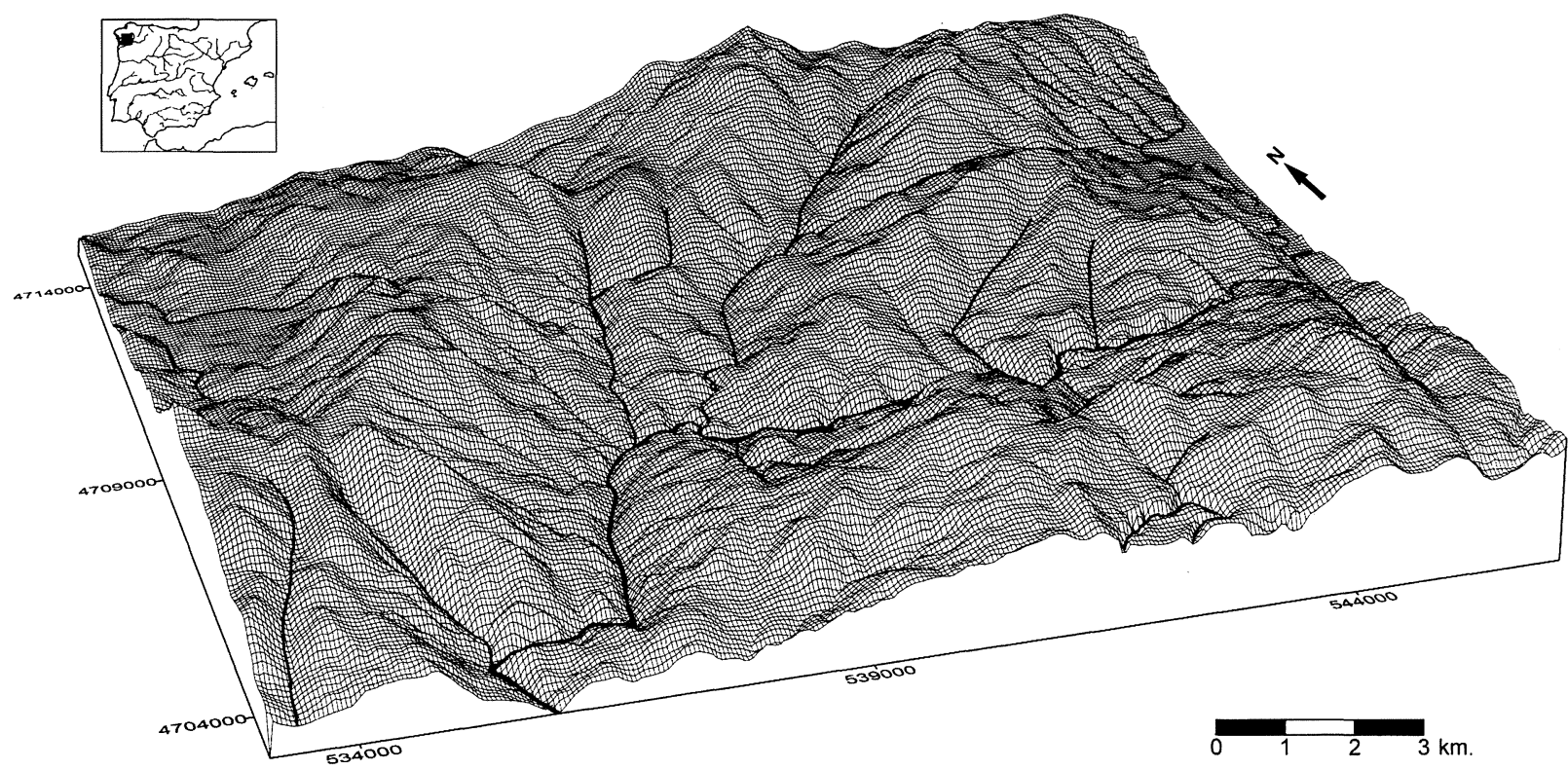

Fig. 2. Modelo tridimensional de relieve de la zona, con los principales ríos.

ca del ayuntamiento de Cotobade (3), es posible integrar la totalidad de los datos en una perspectiva de conjunto. De este modo hemos podido avanzar notablemente en varios aspectos:

- conocer la distribución de yacimientos arqueológicos de diversas épocas (no sólo petroglifos), incluyendo varios de naturaleza invisible; rural;

- estudiar la geografía de la zona y su historia

- inspeccionar a nivel de muestreo el subsuelo gracias a la apertura de la pista y zanja del oleoducto.

\subsection{La Geografía Física}

La zona de trabajo se localiza en la franja Oeste de Galicia, en concreto dentro de lo que podríamos denominar tierras pre-litorales (Fig. 1), cercanas a la faja costera y que ejercen de transición entre la línea de costa y las tierras interiores. El relieve es en general abrupto, de altitudes absolutas no muy importantes (por debajo de $600 \mathrm{~m}$.) pero de fuertes pendientes y escasez de superficies llanas (Fig. 2).

(3) Proyecto denominado «Catalogación e delimitación planimétrica dos xacementos arqueolóxicos do concello de Cotobade», realizado por M. Santos Estévez e I. Vilaseco Vázquez para la Consellería de Cultura de la Xunta de Galicia, entre octubre de 1996 y enero de 1997.
El elemento fisiográfico más determinante es, sin duda, el río Lérez, que atraviesa la zona en ángulo y que en su desembocadura da origen a la ría de Pontevedra. Pese a la escasa distancia que lo separa aquí del mar, el Lérez discurre notablemente encajado, formando un profundo cañón con escarpes laterales que superan en puntos los $100 \mathrm{~m}$. de desnivel. Esto limita las zonas de vadeo a varios puntos muy localizados, cuyo uso como tales está históricamente documentado desde antiguo, como luego veremos. De forma semejante los pequeños arroyos tributarios del Lérez se encierran en cursos igualmente encajados, aunque de menor entidad. De esta forma el río se erige como un límite natural muy claro, que de hecho sirve como frontera no sólo de parroquias sino también de los términos municipales de Campo Lameiro y Cotobade, salvo en un lugar específico que analizaremos más adelante, en el cual la parroquia de S. Xurxo de Sacos se adentra ligeramente al Norte del río (Fig. 3) (4) .

Las tierras que se abren a ambas márgenes del río se caracterizan por poseer fuertes pendientes y un relieve marcadamente abrupto. Hacia el Norte se abre la zona de relieve más tendido, sobre la que se asienta la mayor parte de la población y nú-

(4) En adelante nos referiremos a este lugar como el área de Fentáns, por ser ésta la única aldea del lugar. 


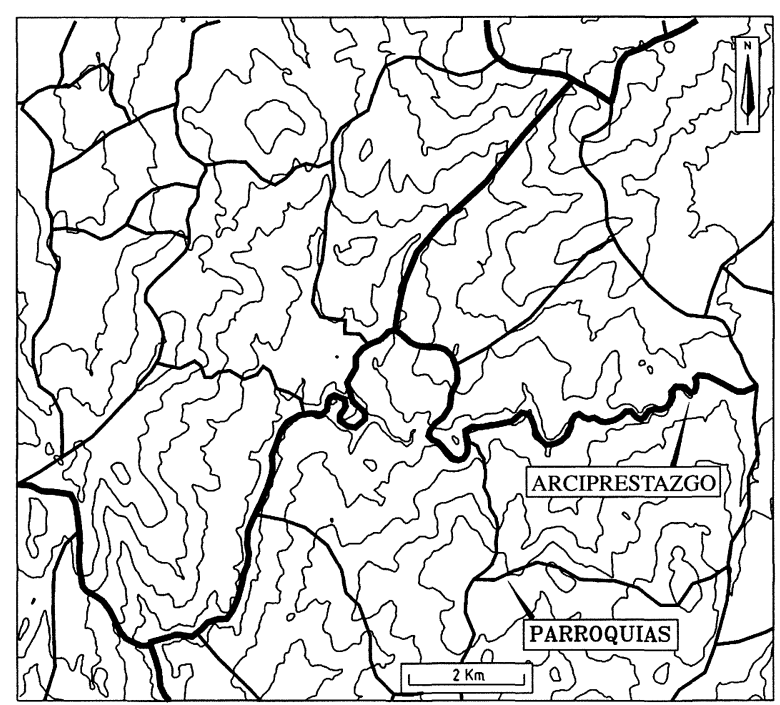

Fig. 3. Límites de parroquias (trazo fino) y arciprestazgos (trazo grueso).

cleos habitados del municipio de Campo Lameiro; esta zona aparece cerrada por sucesivas líneas de divisoria, que la aíslan de otras áreas de valle vinculadas ya a unidades diferentes. Al Sur, sin embargo, las pendientes a partir del Lérez son mucho más fuertes y la línea de divisoria interfluvial está muy próxima al río, lo que hace que las tierras ocupadas se limiten a una estrecha banda localizada a media ladera o bien a las zonas superiores de la línea de montes.

Si trazásemos un transepto ideal Norte-Sur de la zona podríamos aislar las siguientes Unidades de relieve (Fig. 4):

Unidad 1: vertientes escarpadas sobre el Lérez $\mathrm{y}$, en menor medida, sobre algunos de sus arroyos

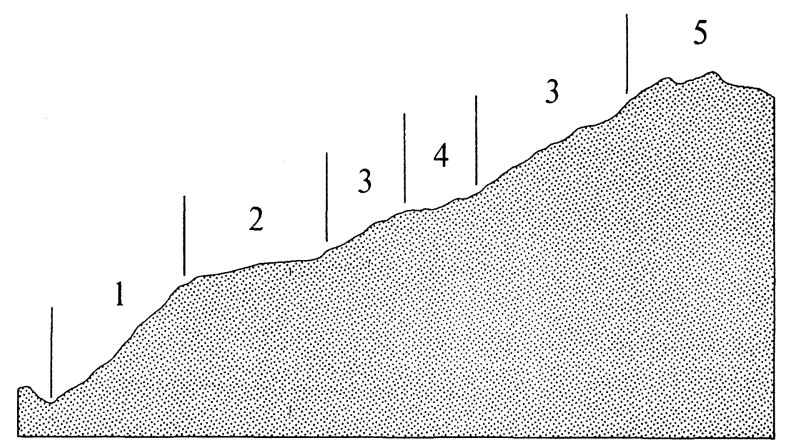

Fig. 4. Unidades de relieve sobre un perfil ideal de la zona.

T. P., 54, n. $^{\circ} 2,1997$ tributarios. Se localizan en ambas márgenes del río y durante todo su recorrido, aunque tienden a ser más amplias en la margen izquierda (lado de Cotobade). La intensidad de estas vertientes decrece en zonas puntuales, que coinciden con los lugares de vadeo tradicionalmente utilizados. Un buen ejemplo se localiza en el área de Fentáns y coincide con el punto en que el límite de la parroquia de S. Xurxo de Sacos y el municipio de Cotobade sobrepasan el río. Los condicionantes que imponen las fuertes pendientes y los suelos muy ligeros limitan su aprovechamiento a área de bosque.

Unidad 2: escalón de relieve más suave, tierras propiamente de valle. Este tipo de tierras bajas y abiertas son poco frecuentes y se reparten de forma muy localizada. Destacaremos como la más amplia el arco en que se sitúan las parroquias de Fragas, Campo y Muimenta, en el municipio de Campo Lameiro, al Norte del Lérez. Es claramente la superficie de valle más significativa y en ella se concentran actualmente las tierras de labradío y uso intensivo, así como la práctica totalidad del poblamiento del municipio de Campo Lameiro. Una segunda localización para este tipo de terreno es al Sur del río, sobre todo en el pequeño arco situado en torno a San Xurxo de Sacos, aunque la superficie es más reducida y la pendiente superior. Igualmente al Sur del Lérez hay otras pequeñas áreas en las que se abren terrenos pertenecientes a esta Unidad, pero se trata de extensiones limitadas y puntuales, coincidentes casi siempre con los núcleos de las respectivas parroquias.

Unidad 3: escarpes laterales de sierra. Este terreno rodea y encierra al anterior en casi toda la zona de trabajo. Se trata de laderas por lo general bastante abruptas, aunque de pendiente variable; accidentadas y escarpadas, al Sur o al Oeste, frente a una pendiente más tendida hacia el Norte o Nordeste, que posibilitan el desplazamiento y el acceso a las zonas bajas. Ésta es la típica localización de terrenos de monte (en el sentido gallego del término, esto es, tierras de aprovechamiento extensivo), hoy día repoblados u ocupados por el monte bajo y matorral pero, en cualquier caso, con escaso aprovechamiento.

Unidad 4: superficies planas en los interfluviales en las que se acumula la humedad y que dan lugar bien a brañas, bien a simples cubetas húmedas. Son áreas de reducida extensión y localización puntual, aunque relativamente frecuentes, sobre todo en la parte alta de los montes que cierran 
nuestra zona por el Norte y Sur. Una localización alternativa viene dada por divisorias de agua de menor entidad, como por ejemplo el área de Fentáns. Los suelos húmedos, permanentes o semipermanentes, limitan el aprovechamiento de estas áreas, aunque las hacen lugares idóneos para la reserva de pasto en la estación seca.

Unidad 5: cimas de las divisorias de aguas principales, de las líneas de montes que cierran la zona de trabajo en casi todo su perímetro. Son lugares rocosos, con suelos muy ligeros o inexistentes y de aprovechamiento extensivo (pastoreo semi-libre, monte bajo o incluso repoblaciones) o nulo. En algunos puntos estas cimas no son tales, sino que se abren en áreas de altiplanicie con abundancia de cubetas húmedas propias de la Unidad 4.

A partir de esta descripción a grandes rasgos podemos entrar en un análisis más detallado de algunos aspectos geográficos. En concreto, y en virtud de la diferente combinación de las unidades antes delimitadas, podemos adoptar ahora una perspectiva horizontal sobre el terreno y definir dos Sectores fundamentales: el valle medio del Lérez y el inicio del valle alto (Fig. 5). A ellos podría unirse un tercer sector, localizado hacia el Oeste de los precedentes y que difiere ligeramente de ambos:

Sector A. Comprendería el área central de la zona de trabajo. Se caracteriza por las formas más abiertas y las más claras cuencas de poblamiento, con una amplia superficie ocupada por terrenos de

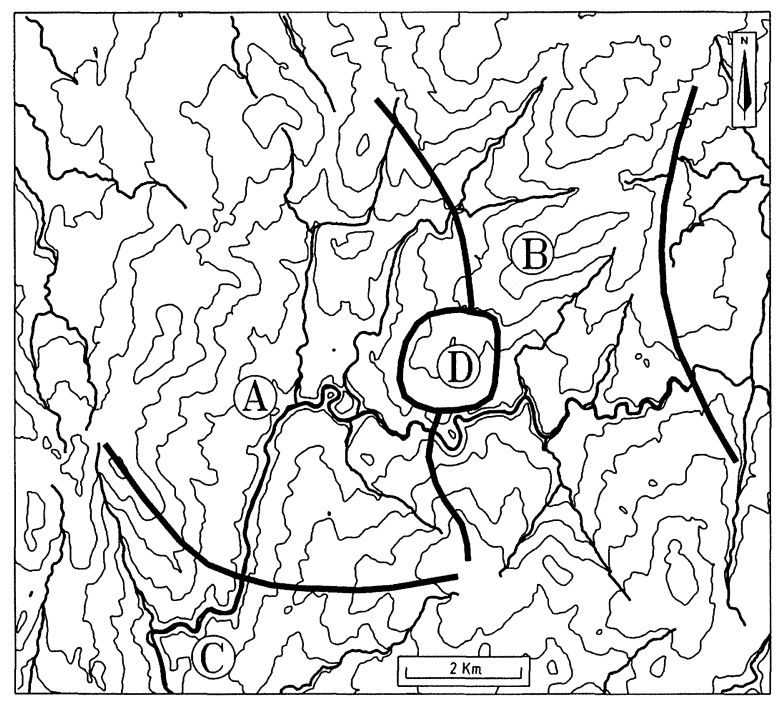

Fig. 5. Sectores de relieve. la Unidad 2. Las pendientes son en general moderadas, a pesar de que en los extremos aparecen terrenos que se engloban en las Unidades 3 ó 5 . Es el área en la que el curso del río aparece menos encajado, y por ello aquí se localizan la mayor parte de los escasos puntos de vadeo, y desde luego los más importantes. Predominan las tierras de labradío y es importante el poblamiento, especialmente en la margen derecha del río.

Sector B. La parte más al Este representa el inicio del valle alto del Lérez. Se individualiza por ser un área de relieve especialmente abrupto y escarpado, con las vertientes del río notablemente verticales y con el curso del Lérez profundamente encajonado, conformando casi un cañón. Las Unidades predominantes son las 1 y 3 . Más allá del río las vertientes se continúan en pronunciadas laderas que ascienden casi directamente hacia los puntos altos de las divisorias, dejando apenas lugar para la apertura de pequeñas zonas más suaves en las que se concentra el escaso poblamiento y actividad agraria de este sector.

Sector $\boldsymbol{C}$. Repite en cierto sentido las características del anterior, aunque un poco menos acusadas. Si bien el río discurre encajado, la altitud relativa a que lo hace es menor con respecto a las vertientes y divisorias. Además en este sector se observa, sobre todo en la orilla izquierda del río, un escalón a media ladera en el que las pendientes se suavizan y es posible el aprovechamiento agrícola y la ocupación; este escalón habilita, además, una zona apta para el desplazamiento.

De esta forma nos encontramos con una disposición aproximadamente simétrica del medio natural, en la que un área central, que ofrece las mejores condiciones para la ocupación y el aprovechamiento agrícola intensivo, se ve flanqueada por dos sectores más agrestes y cerrados que, en cierto sentido, la aíslan. De todas formas conviene resaltar las diferencias que separan a estos dos últimos sectores y que hacen al B mucho más individualizado y peculiar que el C, más semejante al primero. En este sentido no se observa una ruptura brusca entre los Sectores A y C, sino más bien una transición progresiva en la que el terreno se va abriendo y ampliando cada vez más.

Por el contrario sí que existe un punto de inflexión claro entre los Sectores A y B, lo suficientemente importante como para considerarlo un sector más, el Sector $\boldsymbol{D}$. Se trata de una dorsal de aparentemente poca entidad, pero con un emplazamiento muy significativo. Es una superficie de 
reducidas dimensiones, que arranca prácticamente desde el río y asciende hasta enlazar y perderse en los escarpes que cierran la zona por el Este. Si nos referimos a las Unidades anteriormente definidas, podemos observar cómo en este sector son especialmente significativas dos de ellas: la 1 , conformada por los primeros metros de la vertiente que asciende desde el río, y la 4, con una especial concentración de cuencas húmedas sobre los terrenos más o menos llanos que coronan esta pequeña divisoria y se extienden hasta el inicio de los escarpes del sistema interfluvial.

No se trata de una zona que se individualice claramente por razones orográficas; no constituye un Sector homogéneo y claro como los anteriores. Su singularidad geográfica viene dada por razones más bien históricas y culturales que se considerarán a continuación.

\subsection{El presente tradicional: Geografía e Historia Rural}

Este nivel de estudio debe incorporar tanto la documentación sobre la historia más reciente como el análisis del poblamiento tradicional de la zona. Se debe hacer nuevamente desde una perspectiva formal, que contribuya a la descomposición y comprensión del paisaje campesino tradicional y de sus características geográficas (de aquello que puede permanecer por pertenecer al orden de la naturaleza y que se recupera o influye en diferentes periodos).

En este sentido, hay un conjunto de evidencias que destacan la importancia del Sector D. En primer lugar esta zona coincide con el área de Fentáns, a la que ya nos hemos referido con anterioridad como una de las zonas de vadeo del río más claras, históricamente documentada por, entre otras cosas, la toponimia y la presencia de algunos puentes. Además esta zona presenta una interesante singularidad territorial, ya que en ella el claro límite impuesto por el río Lérez se quiebra; así el área de Fentáns, pese a estar físicamente vinculada a las parroquias del municipio de Campo Lameiro, pertenece a la de San Xurxo de Sacos, del municipio de Cotobade.

Todavía se pueden derivar más cosas del análisis de la distribución parroquial. En efecto, si se observa el mapa de parroquias (Fig. 3) llama la atención la disposición radial de varias de las feligresías del municipio de Campo Lameiro (Campo, Muimenta, Morillas y Montes) y de la propia de San Xurxo de Sacos con respecto a la zona de Fentáns, disposición extraña y que no se repite en ningún otro lugar de la zona. Podría pensarse que este reparto parroquial, y el propio hecho de que el área de Fentáns pertenezca a San Xurxo de Sacos, tiene un origen más o menos reciente. Sin embargo ya en los interrogatorios hechos para el Catastro del marqués de la Ensenada, hacia 1756, el lugar de Fentáns pertenece a San Xurxo de Sacos y los límites parroquiales por el Norte son los mismos que en la actualidad (5). Tenemos, pues, una cierta garantía del funcionamiento de esta división parroquial durante varios siglos, y todavía se puede pensar en una antigüedad mayor si admitimos la suposición generalizada de los escasos cambios en la estructuración parroquial de Galicia entre la Edad Media y el siglo XIX.

Otro elemento de interés es que, además de marcar la separación entre parroquias y municipios, en esta zona convergen actualmente los límites de tres arciprestazgos diferentes: los de Montes, Moraña y Cotobade (Fig. 3). Esta situación puede retrotraerse hasta, al menos, el año de 1607, cuando el Cardenal Jerónimo del Hoyo (1950) elabora sus memorias, en las que describe la extensión y organización del arzobispado de Santiago, al cual pertenecían (y pertenecen) los tres arciprestazgos. A la luz del mapa de límites de los arciprestazgos cabría esperar que el punto de unión entre ellos se encontrase no en el final de la parroquia de Morillas, sino en la de Montes, que es por donde discurre exactamente la divisoria. Sin embargo la parroquia de Morillas no es una parroquia matriz sino anexa (dependiente) de la de Montes; así pues el hecho significativo es que Montes pertenece a un arciprestazgo diferente y, con ella, su parroquia anexa Morillas, por lo que, si no físicamente, sí al menos lógicamente, el límite de los arciprestazgos viene a coincidir de nuevo con la divisoria de Fentáns.

Vemos, pues, como el área de Fentáns adquiere una serie de denotaciones tanto geográficas como histórico-culturales que la señalan como un lugar destacado físicamente y revestido de un significado especial desde, al menos, la Edad Moderna y, supuestamente y con bastante certeza, la época medieval.

(5) Hemos identificado algunas variaciones en los límites y composición de las parroquias en varios puntos de la periferia de nuestra zona de trabajo desde, al menos, 1607. Sin embargo, ni en el área de Fentáns ni en el conjunto de las parroquias centrales de la zona hemos podido documentar ninguno. 


\subsection{El pasado arqueológico}

Poblamiento medieval

Para evaluar los patrones de localización de las aldeas medievales disponemos de dos clases de datos. En primer lugar bastantes fuentes documentales nos permiten conocer con cierta exactitud la distribución de los lugares habitados hacia fines de la Edad Moderna (Fig. 6), lo cual, del mismo

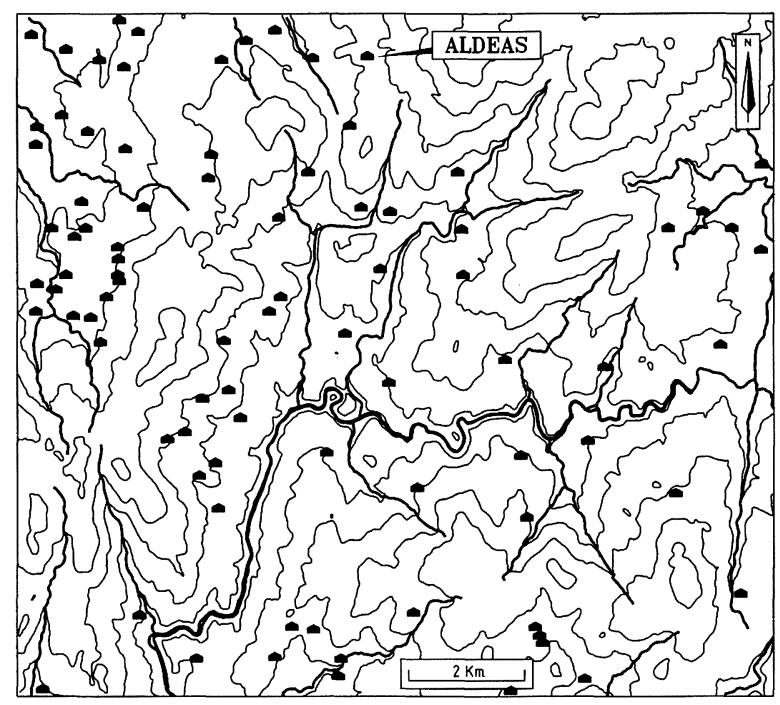

Fig. 6. Distribución del poblamiento tradicional en 1867.

modo que ocurría con los límites de las parroquias, permite una cautelosa extrapolación hacia atrás. En segundo lugar los trabajos puramente arqueológicos también desvelan la existencia de algunos yacimientos medievales que, en consonancia con lo dicho anteriormente, se ubican en las proximidades de aldeas tradicionales y podrían indicar un cierto proceso de desplazamiento de los lugares de habitación respecto a los de momentos anteriores hacia finales de la Edad Media. En todo caso la distancia entre los yacimientos y las aldeas actuales es muy escasa y además ambos ofrecen un patrón de emplazamiento casi idéntico.

El poblamiento medieval (y posterior) muestra una preferencia muy clara por los Sectores A y C, con una menor densidad en el B y una ausencia total en el D. Más clara es todavía su relación con la Unidades planteadas, ya que las aldeas de este momento se ubican casi exclusivamente en tierras de la Unidad 2, áreas de valle y labradío, o en el límite entre éstas y las de la Unidad 3.

\section{Yacimientos romanos}

Nos encontramos ante un vacío de datos casi total, aunque a tenor de lo que es habitual en el registro gallego cabe suponer que estos asentamientos estarían localizados en las zonas más bajas y con mejores posibilidades productivas (esto es, la Unidad 2). Sólo contamos con datos directos acerca de otras dos facetas del registro arqueológico de este período: vías e inscripciones.

En relación con el posible paso de la vía XIX Bracara-Asturica por esta zona, las propuestas son muchas y las posiciones se pueden resumir entre quienes aceptan ese paso y quienes optan por situar el trazado de la ruta en un punto más cercano a la costa (ver una síntesis en Peña, 1990-1). Al margen un poćo de esta polémica, lo que sí parece claro es la existencia de algún tipo de vía de comunicación, sea o no la vía XIX. Su trazado posible, basándose tanto en restos de calzadas antiguas como en la existencia de puentes, zonas de vadeo y la toponimia, es el que se propone en la figura 7 (6). Esta línea de tránsito, por otra parte bien documentada en época medieval, atravesaría la práctica totalidad de Unidades arriba definidas, aunque con cierta tendencia a evitar las vertientes más escarpadas o las zonas más húmedas.

En cuanto a las inscripciones rupestres (Fig. 7), su lectura e interpretación no son por el momento claras, pues no hemos encontrado paralelos para ellas (Fig. 8). A pesar de desconocer su sentido exacto, las semejanzas de estilo y emplazamiento con otras inscripciones rupestres del Noroeste (Rodríguez Colmenero, 1993) y el hecho de estar presumiblemente en latín (7) son argumentos en favor de su adscripción a época romana como hipótesis más verosímil. En cualquier caso no se trata obviamente de inscripciones latinas "clásicas" u "oficiales", sino más bien de la obra de indígenas que imitan, con distinta suerte, una práctica ajena a su cultura. Esto da lugar a un producto que no es totalmente indígena ni romano, pero que quizá convenga más interpretar desde los parámetros culturales indígenas.

(6) La indagación sobre este tema y propuesta de trazado se debe a nuestro compañero Fidel Méndez Fernández.

(7) Podría tratarse de iniciales o abreviaturas de otras palabras no latinas, pero por el momento no nos parece la suposición más plausible. 


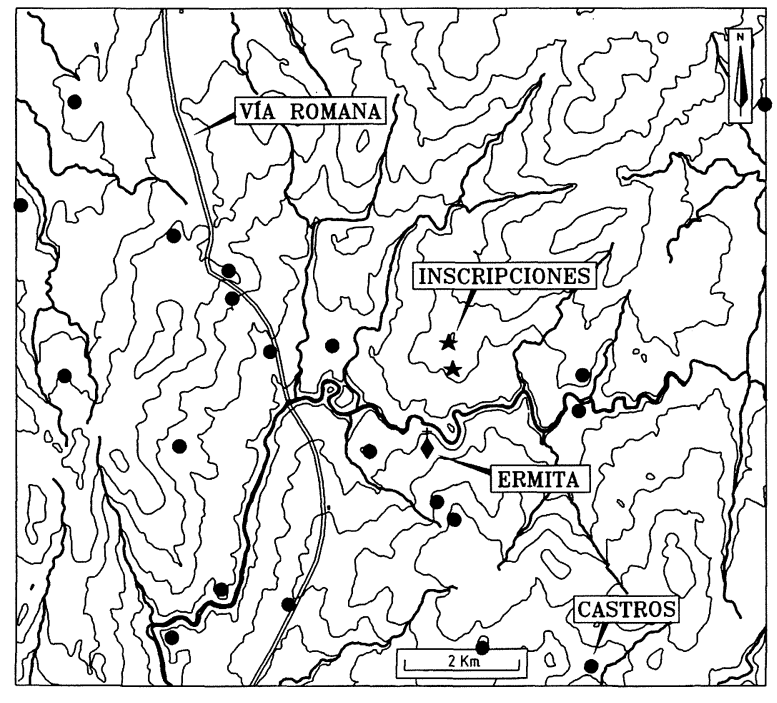

Fig. 7. Localización de los castros, inscripciones y la ermita de San Xusto, con el trazado hipotético de la vía romana XIX.

Las dos inscripciones se emplazan en puntos muy próximos (Fig. 7), ocupando el eje de la pequeña divisoria que cierra el área de Fentáns por el Este. Ocupan, así pues, una posición dentro de las tierras del Sector D, en una zona en la que predominan las superficies de la Unidad 4. No obstante,
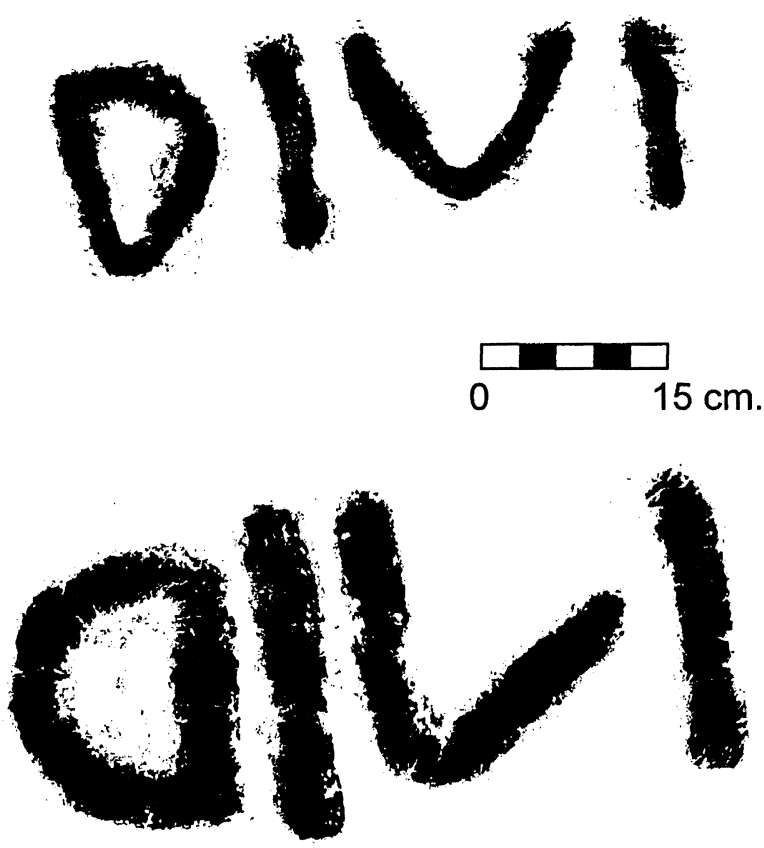

Fig. 8. Calcos de las inscripciones. si atendemos más en detalle a su emplazamiento vemos que se encuentran justo sobre una línea de divisoria, la principal de la zona, que separa varios grupos de cuencas húmedas propios de la Unidad 4 pero que, como tal divisoria, podría incluirse más bien dentro de la Unidad 5, pese a su escasa altitud absoluta y a no ser exactamente una zona de cumbres. Esta divisoria es, además, la línea que separa los sectores A y B.

\section{Castros de la Edad del Hierro}

Llama la atención la concentración de castros en un área bastante restringida. Frente a su presencia frecuente en los terrenos propios de la Unidad 2 o en el límite entre éstos y los de la Unidad 3, se constata una ausencia absoluta en la Unidad 1 y en las tierras más escarpadas de la Unidad 3. En las dos restantes unidades (4 y 5) existen algunos ejemplos de castros, aunque su presencia es menos habitual.

Por otra parte es quizá más llamativa la absoluta concentración de yacimientos de la Edad del Hierro en el Sector A y las tierras más suaves del $\mathrm{C}$, que guardan bastantes características en común. En contraste los sectores $\mathrm{B}$ y D registran una ausencia casi absoluta de castros, con un único ejemplo dudoso en la zona B.

En la figura 7 hemos incluido algunos yacimientos no pertenecientes a la zona de estudio con la finalidad de mostrar cómo los vacíos que se observan en la distribución se corresponden en general a los puntos de divisoria que separan nuestro sistema de otros anejos. Este hecho es especialmente claro hacia el Oeste, Norte y Este, donde los próximos castros en aparecer se vinculan ya a sistemas de valle diferentes, aunque no deja de observarse también en el Sur.

\section{Petroglifos de la Edad del Bronce}

Se localizan en los cuatro Sectores definidos. Sin embargo su distribución según Unidades es más restrictiva (Fig. 9): aparecen tanto en los escarpes de sierras (Unidad 3) como, sobre todo, en las zonas llanas vinculadas a cuencas de reserva de humedad (Unidad 4) (8), y excepcionalmente

(8) Las tierras de esta Unidad 4 acogen el $80 \%$ del total de los grabados de la zona.

T. P., 54, n. $^{\circ} 2,1997$ 


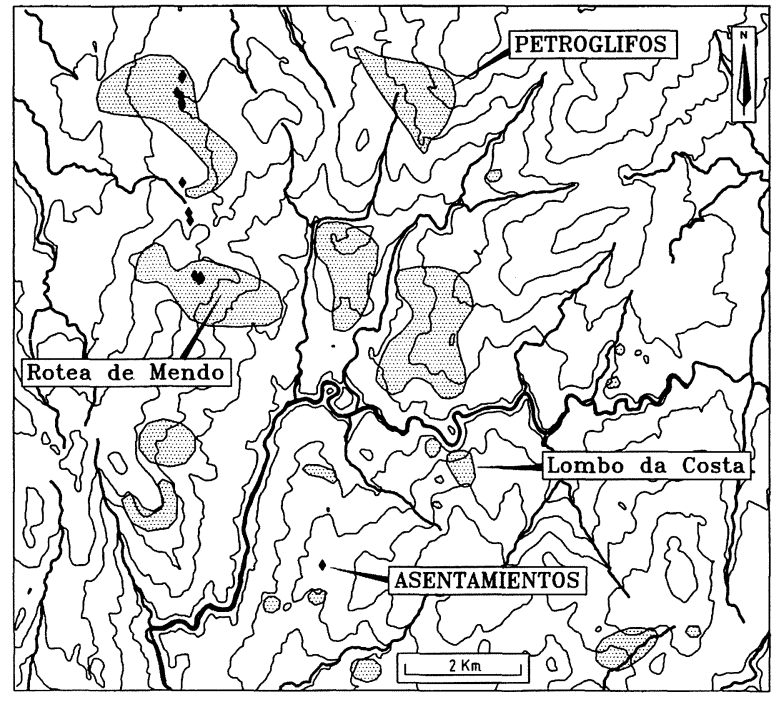

Fig. 9. Principales grupos de petroglifos de la Edad del Bronce y yacimientos conocidos de la prehistoria reciente. Se especifican los conjuntos de Rotea de Mendo y Lombo da Costa.

también en las cimas de divisorias (Unidad 5). En las Unidades 1 y 2 no aparecen. Se podría considerar que su ausencia en esta Unidad 2 se debiese al efecto de los trabajos agrícolas intensivos, pero el hecho de que no se haya localizado ninguna excepción nos hace pensar como posibilidad más plausible que originalmente no existieron.

Los petroglifos se vinculan con preferencia a dos elementos del paisaje: a zonas húmedas de reserva de pasto, como son las cuencas de recepción y brañas habituales en las tierras de la Unidad 4; y a las líneas de movimiento y tránsito, en especial a los puntos de paso más significativos como, por ejemplo, el área de Fentáns, asociada como ya apuntamos a una zona de vadeo del río y relacionada con una línea de ascenso a partir del paso del Lérez.

\section{Yacimientos Neolíticos y del Bronce}

Gracias sobre todo a los trabajos de seguimiento de la obra del Oleoducto, se han podido detectar una serie de yacimientos abiertos, que por su naturaleza invisible son muy difíciles de identificar en condiciones de prospección superficial. Puede considerarse que la mayor parte de ellos pertenecen al II milenio o, en algún caso, a momentos algo anteriores, aunque la claridad del registro varía bastante según los casos. De cualquier forma lo que está fuera de duda es su carácter de yacimientos habitacionales prehistóricos (Criado et alii, e.p.).

Su distribución (Fig. 9) está condicionada por la línea seguida por la zanja del Oleoducto. De todas formas podemos descubrir así los patrones de emplazamiento que adoptan estos asentamientos. Este muestreo es bastante significativo ya que el transepto analizado (Fig. 1) atravesó todo el espectro de Unidades establecidas.

Los asentamientos se encuentran sobre los Sectores A, B y C, y no se han documentado ninguno en el Sector $\mathrm{D}$, a pesar de que también ha sido una zona intensamente estudiada gracias, entre otras cosas, a la prospección de pistas, cortafuegos y al reciente seguimiento de una repoblación forestal (9). En cuanto a unidades los yacimientos aparecen siempre vinculados a terrenos de la Unidad 4 , en estrecha asociación con cubetas y zonas de tránsito. Por esto mismo resulta llamativa su ausencia en el Sector D, que como se recordará acoge abundancia de estas cubetas y es una marcada línea de movimiento.

\section{Túmulos megalíticos}

Los únicos túmulos que se conocen se sitúan en la periferia de la zona de estudio, siempre en tierras pertenecientes a las Unidades 4 y 5 . Se trata de concentraciones de diferente entidad que, como se puede apreciar, se sitúan sobre las líneas de divisoria interfluvial que delimitan la zona definida para el trabajo (Fig. 10).

El patrón de emplazamiento de los túmulos sigue, a grandes rasgos, una asociación a líneas de movimiento y a cuencas de recepción de humedad con presencia de brañas o cubetas. Es llamativa su ausencia en el Sector D, a pesar de la abundancia en él de ambos tipos de elementos: cubetas húmedas y línea de movimiento importante. Ya hemos citado más atrás la posible existencia de yacimientos habitacionales vinculados a los túmulos; volveremos más adelante sobre ello.

\section{LA DECONSTRUCCIÓN DEL ESPACIO (ANÁLISIS)}

Mostrados los datos, podemos proceder a un análisis en el que contrapondremos los diferentes espacios definidos por los yacimientos de cada

(9) Ver la segunda nota de este trabajo. 


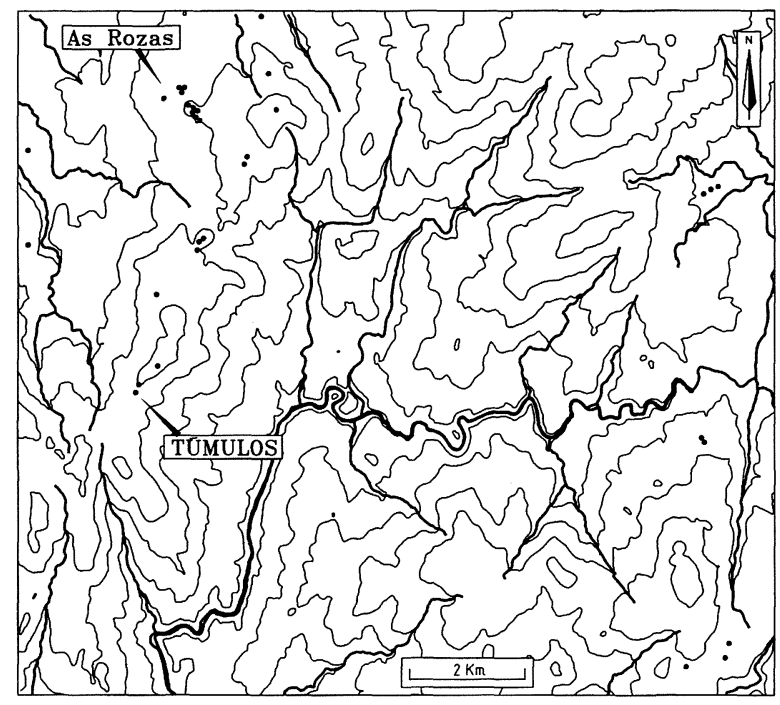

Fig. 10. Distribución de túmulos megalíticos, con la localización de la necrópolis de As Rozas.

etapa, de forma que se destaquen las correspondencias que existen entre ellos y podamos entender así los modelos de organización espacial en cada uno de esos momentos.

Estas correspondencias son de dos tipos: entre diversas clases de yacimientos, y entre yacimientos y Unidades/Sectores geográficos; son respectivamente las correspondencias diacrónica y sincrónica definidas en el apartado 1. En la práctica ambos tipos se solapan con frecuencia, lo cual incide todavía más en marcar la correlación entre determinados modelos de organización espacial.

Una primera relación de interés se establece entre túmulos, yacimientos habitacionales abiertos de la Edad del Bronce y petroglifos de motivos más sencillos con predominio de cazoletas. Estos elementos suelen aparecer físicamente muy próximos y visualmente conectados, como es claro en una de las zonas más intensamente trabajadas y mejor conocidas (As Rozas, al noroeste de la zona de trabajo; Villoch, 1995). Esta asociación se ve reforzada por la coincidencia habitual con las formas fisiográficas pertenecientes a la Unidad 4. Además suele tratarse de lugares propicios para el movimiento y que funcionan como áreas de tránsito, (cruces, collados, dorsales, etc.).

Como contraposición, un segundo bloque viene marcado por la proximidad física y relación visual entre castros de la Edad del Hierro, el poblamiento medieval y las aldeas tradicionales. Esta asociación es muy característica, y se relaciona con terrenos propios de la Unidad 2, que componen ya no líneas de movimiento sino cuencas, $u n i$ dades cóncavas de ocupación (10). La significación de estas cuencas para la estructuración del poblamiento tradicional se documenta en el hecho de que cada una de ellas se corresponde en líneas generales con los límites de una parroquia (unidad territorial fundamental del poblamiento gallego) o, a una escala todavía más reducida, de un lugar o aldea (componente básico de ese poblamiento). En la figura 6 se puede observar la correspondencia entre relieve, límites parroquiales y distribución del hábitat.

Al margen de esta serie de asociaciones se encuentran los petroglifos con paneles complejos, formados por motivos naturalistas (animales, armas, figuras humanas) y combinaciones elaboradas de elementos circulares, cazoletas, etc. Se localizan en la periferia de zonas pertenecientes a la Unidad 4 (cubetas, etc.) pero fuera de ellas, sobre terrenos habitualmente en pendiente y que más bien señalan la transición entre esa Unidad y la 3 (escarpes, laderas). A una escala más concreta se observa que los petroglifos de este tipo ocupan terrenos de cierta pendiente, dentro más bien de la Unidad 3, aunque siempre en la transición hacia áreas más llanas. De cualquier forma su patrón de distribución y ocupación del medio es peculiar, diferente de cualquier otro elemento del registro y, en especial, distinto de otros tipos de grabados rupestres más simples.

La distribución por Sectores no es, en principio, especialmente significativa. Obviamente hay Sectores en los que predominan uno u otro tipo de yacimiento, pero ello es sólo en función del predominio de uno u otro tipo de Unidades en cada Sector; en otras palabras, el elemento determinante en la localización de los asentamientos en las distintas épocas es la Unidad y no el Sector geográfico.

Sin embargo hay una excepción. El Sector D,

(10) Este concepto ha sido definido y utilizado en trabajos anteriores, particularmente Criado, 1991: 250 y Parcero, 1995: 134. Con él nos referimos a las unidades fisiográficas menores que se pueden diferenciar en el medio gallego; las condiciones ecológicas posibilitan que en ellas, que se corresponden generalmente con pequeñas cuencas o sectores de valles, se puedan practicar a lo largo de las pendientes laterales los diferentes tipos de uso del suelo en los que se basa el sistema tradicional gallego: inculto, pasto natural, agricultura de roza, producción de toxo, agricultura intensiva, prado y bosque. La definición de espacios cóncavos es un procedimiento analítico que ayuda a comprender la organización de un determinado territorio y la distribución del hábitat dentro de él. 
contrariamente a los demás, ofrece una notable densidad de petroglifos de todos los tipos y las únicas inscripciones indígeno-romanas conocidas de la zona. Sin embargo no hay ningún otro tipo de elemento en él, a pesar de que, por ejemplo, podría ser un lugar adecuado para la existencia de asentamientos de la Edad del Bronce, de túmulos o incluso de aldeas tradicionales, que sólo ocupan su periferia. Se trata, pues, de una zona liminal, marginal para el poblamiento desde posiblemente la Edad del Bronce. Esta marginalidad se aprecia claramente al observar cómo la distribución de los núcleos parroquiales más cercanos (Fig. 3) aisla a esta zona en el centro, como una especie de referencia alrededor de la cual se distribuyen las parroquias pero que no pertenece claramente a ninguna (la propia estructura de las parroquias tiende a señalar lo mismo, como vimos más arriba). Frente a otras áreas vacías de elementos arqueológicos (las divisorias o cimas más altas de la zona), las diferencias son notables: este Sector D no es un lugar de difícil acceso, no se localiza a una altura importante, las pendientes no son especialmente fuertes y, además, no hay una ausencia absoluta de elementos arqueológicos, sino una presencia selectiva.

Otro elemento que destaca la especificidad de este Sector D es una línea imaginaria que lo atraviesa en sentido Norte-Sur y que establece el límite de la distribución de elementos arqueológicos en todos los momentos, quedando hacia el Este una amplia zona (en esencia el Sector B) en la que, salvo muy concretas excepciones, las evidencias de ocupación desaparecen (Fig. 6) hasta Cerdedo, excepción hecha del poblamiento histórico (11). La continuación de esta línea imaginaria en la orilla opuesta (Sur) del Lérez coincide con la aparición de dos elementos arqueológicos del mayor interés:

- Una nueva concentración de petroglifos de notable riqueza en el conjunto denominado Lombo da Costa, con abundancia de motivos complejos, elementos naturalistas, etc. Este hecho señala la importancia de este punto en la Edad del Bronce, a pesar de ser un lugar en el que apenas aparecen cubetas húmedas o zonas de especial concentración de recursos.

- La ermita y carballeira de San Xusto, lugar

(11) Esto es especialmente significativo al Norte del Lérez. La zona de Cotobade, al Sur, es más peculiar y menos conocida para nosotros, aunque da la impresión de responder a un esquema bastante semejante. dedicado a dos mártires paleocristianos hispanos (Justo y Pastor) cuyo culto, como el de otros mártires de la época, se remonta a los primeros siglos del cristianismo peninsular, para ser progresivamente olvidado y abandonado en la Edad Media; en el siglo XI se había perdido ya la memoria de ese martirio (12). Esto evidencia la temprana sacralización de este lugar (13), de difícil acceso y alejado de las zonas de actividad humana tradicional. Este distanciamiento de los esquemas de racionalidad campesinos, del lugar en que se supone que debe localizarse una ermita, se expresa gráficamente en la copla popular: Carballeira do San Xusto / moitos arrodeos ten / se non fora polos santos / alá non iba ninguén (14) (Fuentes, 1976: 262)

Todo ello nos hace pensar en la posibilidad de encontrarnos ante la sacralización de un lugar de importancia simbólica anterior (hecho frecuente en Galicia a través de, por ejemplo, la construcción de ermitas sobre castros); esto es, en época castreña o indígeno-romana. La continuidad con la otra orilla del río se establecería, en este caso, con referencia a las inscripciones indígenoromanas.

A pesar de la variedad de áreas geográficas y de modelos de ocupación del espacio que se van superponiendo en cada época, lo cierto es que hay un elemento que parece funcionar como eje esencial del territorio en las distintas épocas, en mayor o menor medida: las líneas de movimiento. Estas funcionan de forma muy directa y evidente como condicionantes del emplazamiento de túmulos y petroglifos. Su incidencia sobre la organización del poblamiento posterior es menos clara, ya que los yacimientos parecen dispersarse por zonas más amplias y menos selectivas; sin embargo de su importancia en estos momentos habla su artificialización, que da lugar a caminos pavimentados, puentes, etc., muy claros ya en la Edad Media pero posiblemente también, como vimos, en época romana.

Las líneas de movimiento conforman una red amplia y diversa, de la que destacaremos, por su

(12) Agradecemos a F. López Alsina, profesor de Historia Medieval de la Universidad de Santiago, estos datos y valoración.

(13) A diferencia de otras muchas ermitas de la zona, con advocaciones generalmente marianas, adscribibles a momentos más recientes (ss. XVII-XVIII en adelante).

(14) Una traducción aproximada: «La robleda de San Justo tiene un acceso tan difícil que, de no estar los santos (la ermita), nadie iría allí». 


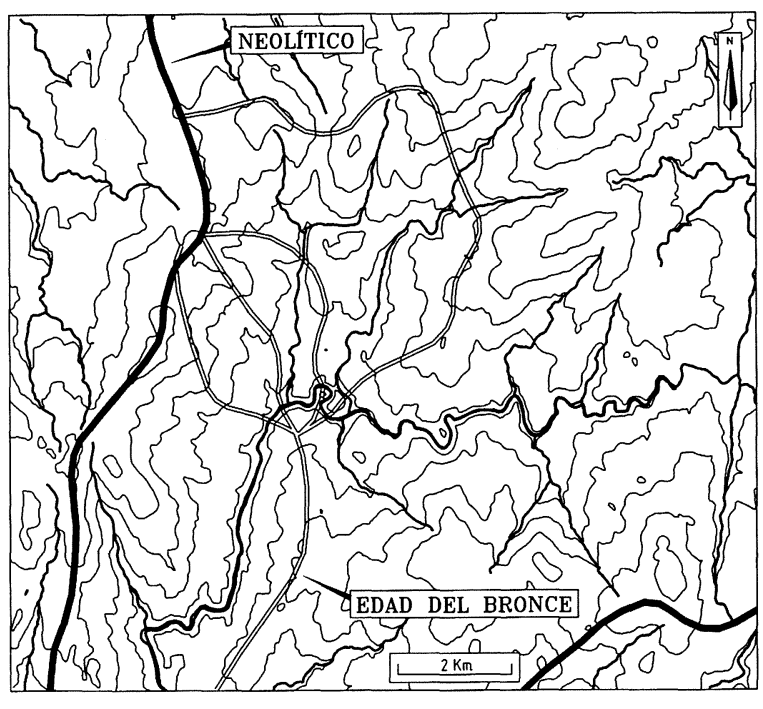

Fig. 11. Líneas de movimiento hipotéticas en el Neolítico (trazo simple) y la Edad del Bronce (trazo doble).

lógica especificidad, aquellos caminos que adoptan una dirección norte-sur, por cuanto permiten el paso del Lérez (Fig. 11). Entre ellos descolla la línea más y mejor documentada en la toponimia y por restos materiales (calzadas, puentes, pero también petroglifos) que atraviesa el Lérez por el área de Fentáns y asciende al Norte adentrándose por el Sector D. La importancia de esta línea de movimiento radica en destacar, una vez más, el papel peculiar e importante de este Sector dentro de la configuración tanto física (como vimos más arriba) como cultural a lo largo de distintos momentos y desde, al menos, la Edad del Bronce en adelante.

\section{EL SENTIDO DEL ESPACIO (RESULTADOS)}

Los datos y análisis que hemos reunido nos permiten deconstruir diacrónicamente los modelos de paisaje social y simbólico que se sucedieron en la zona. Como veremos, estos resultados son coherentes con las formas de paisaje prehistóricos que la investigación en curso desde hace varios años nos permite reconstruir en Galicia (15). Los datos permiten contrastar en parte la validez de los modelos planteados y, en parte, precisarlos.

(15) Se puede ver a Criado et alii, 1991, así como los trabajos contenidos en Criado (dir.) e.p.
Aunque sea con carácter preliminar, nos permiten hacer el estudio diacrónico comarcal más completo en la actualidad para el noroeste peninsular (16). Por otra parte, y más en concreto, este trabajo ofrece una aproximación a una dimensión inédita e interesante de la Arqueología del Paisaje, el estudio de la geografía sagrada prehistórica.

\subsection{La ocupación del entorno}

Como hemos visto, en la zona se detectan una serie de modelos de poblamiento diferentes que se suceden desde el Neolítico hasta la Edad Moderna. El primero de estos modelos, Neolítico, viene definido por la presencia de túmulos como elementos esenciales, acompañados generalmente de petroglifos sencillos (cazoletas o círculos simples). El poblamiento se centra en terrenos altos (Unidades 4 y 5 ), en los que predominan condiciones de vegetación abiertas y suelos ligeros y bien drenados, y se constituye alrededor de pequeñas cuencas que poseen brañas o zonas húmedas. Este nicho es adecuado para la práctica de una estrategia de subsistencia basada en la agricultura de azada y roza y en la explotación de recursos silvestres. En cambio, las zonas bajas y de valle quedan relegadas, posiblemente por resultar inaccesibles debido a la densa cubierta arbórea que habrían poseído en esos momentos. Tanto la distribución de monumentos como los propios asentamientos, allí donde se han podido localizar (por ej. As Rozas) (17), evidencian este patrón de ocupación del terreno.

(16) Hasta la fecha la única zona en la que se conocían exhaustivamente los patrones de poblamiento y construcción del paisaje de la Prehistoria reciente y de Historia Antigua y Medieval, era el área Bocelo-Furelos (Criado et alii, 1991). Aunque la escala de investigación ha sido más intensiva en ese caso que en el que ahora nos ocupa, éste incorpora datos sobre fenómenos y momentos que en aquella zona no se documentaron, particularmente en el arte rupestre de la Edad del Bronce y la situación en época moderna.

(17) En el espacio central de la necrópolis de túmulos existente en esta zona (estudiada en Villoch, 1995), se ha recogido abundante material cerámico y lítico y se ha tenido la oportunidad de excavar una fosa (actuación dirigida por V. Villoch y P. Prieto) que ha ofrecido una datación del 4219+32 BP (2900-2690 cal. BC); aunque los datos no son concluyentes; es posible que evidencien la existencia de un asentamiento contemporáneo a los túmulos (Criado et alii, 1996). Además se han localizado en este mismo tipo de posición toda una serie de puntos con material de adscripción indeterminada pero que, razonando por exclusión, podrían corresponder a yacimientos neolíticos. Todos estos datos fueron aportados por el seguimiento de las obras de construcción del Oleoducto Coruña-Vigo. 
Uno de los elementos esenciales de configuración de este paisaje es el movimiento a través del espacio. Ese movimiento se articula a partir de líneas remarcadas por la presencia de los propios túmulos, líneas que recorren las divisorias de interfluviales y las estribaciones que dan acceso a ellas; los cursos de agua, en especial el Lérez, son barreras para el movimiento y para su vadeo se obliga a amplios desplazamientos hasta encontrar puntos muy accesibles (Fig. 11).

En la Edad del Bronce contamos con dos tipos de elementos del registro arqueológico, que representan respectivamente dos dimensiones de una misma realidad espacial. Por una parte los yacimientos habitacionales ofrecen relación con tierras de la Unidad 4, esto es, con lugares más o menos altos, localizados en torno a áreas abiertas y llanas con cubetas húmedas en su centro. Como complemento, los petroglifos se emplazan en lugares de mayor pendiente, en las zonas de contacto entre los escarpes y esas áreas en torno a cubetas húmedas; de esta forma la relación más frecuente entre ambos consiste en la disposición aproximadamente periférica y más baja (en términos tanto de altitud absoluta y relativa) de los petroglifos respecto a los yacimientos y a las áreas de brañas a ellos asociadas, como se observa con claridad en el caso de, por ejemplo, Rotea de Mendo (Fig. 9).

No obstante, el modelo de paisaje que se conforma en este momento es algo más complejo, en especial por lo que respecta a los petroglifos. $\mathrm{La}$ definición y delimitación de líneas de movimiento sigue ocupando un lugar prioritario, pero las diferencias respecto al Neolítico son notables. En lugar de un tránsito paralelo al río, ahora las líneas se disponen radialmente a partir de éste, destacándose como puntos significados las zonas de vadeo del Lérez. A partir de ellos se accede a los escarpes más suaves, que permiten la conexión entre las tierras altas, en las que se concentran los asentamientos (en zonas adecuadas para el cultivo con tecnología de roza y en torno a brañas que servían como áreas de reserva de pasto) (18), y las tierras bajas, ocupadas por bosque denso (19) y que ofre-

(18) Este modelo de subsistencia y uso del suelo se describe con mayor detalle en Méndez (1994), donde se justifica particularmente el interés del control de las zonas húmedas como recurso para mantener una cabaña de ganado vacuno que habría tenido una gran importancia económica y social en las comunidades de la Edad del Bronce.

(19) Debemos resaltar que esta observación es sólo una hipótesis fundada en la investigación paleoecológica realizada en Galicia. cían en cambio reserva de recursos cinegéticos y silvestres. Las líneas generales de movimiento que funcionan como ejes básicos de articulación del paisaje social aparecen marcadas artificialmente por la presencia de importantes concentraciones de petroglifos (Fig. 9). Una de estas concentraciones, en realidad la más notable por cantidad y variedad de grabados, se dispone en torno al área de Fentáns y ocupa la mayor parte de las tierras del Sector D. Este destacado conjunto de grabados, si bien acota una zona especialmente profusa en cubetas húmedas (tal vez la más notable), rompe la regularidad documentada en otros sectores de la zona, ya que no parece encerrar ningún asentamiento.

En la Edad del Hierro los asentamientos fortificados (castros) constituyen el elemento más significado en la conformación del paisaje. En un primer momento los asentamientos siguen ocupando lugares altos, en la periferia de las divisorias de aguas, como es el caso del temprano castro de Penalba (Álvarez, 1986), situado de hecho a escasa distancia de un yacimiento de la Edad del Bronce con cerámica campaniforme. Sin embargo, a partir probablemente de la Segunda Edad del Hierro, el poblamiento desciende decididamente hacia las tierras bajas, de valle, aunque tiende a localizarse en la transición entre éstas y las zonas de escarpe. El modelo de producción primaria es progresivamente más intensivo y la roturación de zonas de bosque y consiguiente explotación de suelos más fértiles y pesados se hace ahora posible. Por ello es factible localizar en este momento el primer episodio de ocupación sistemática del valle en la historia del mundo rural en el noroeste.

El papel de las líneas de tránsito como elementos esenciales en la conformación del paisaje parece desaparecer, o al menos diluirse. En su lugar parece asentarse un paisaje más estático, estructurado más bien a partir de puntos fijos y concretado en territorios; ello estaría, por otra parte, en lógica relación con la aparición de la agricultura de campos permanentes y la superación definitiva del modelo de producción extensivo y, en cierta medida, semi-móvil de la Edad del Bronce (Criado, 1989 y 1991; Méndez, 1994). Es así cómo se entiende la aparición de un nuevo tipo de elemento del registro arqueológico: las inscripciones rupestres. Su localización en el Sector D, en la línea de divisoria entre dos grupos de relieve bien determinados, en la línea que cierra visualmente la zona de valle, en el límite entre el área ocupada y la va- 
cía de poblamiento, inciden en señalar su carácter tanto de delimitadores territoriales como de hitos que dotan de valor simbólico a un espacio concreto, ciertamente distinto del área de ocupación y, además, en su límite.

La temprana Edad Media supone una profundización y la definitiva consolidación del proceso de ocupación de las tierras bajas. Las evidencias de poblamiento específicamente altomedieval no son demasiadas, pero es bastante posible que la amplia ocupación del territorio que se percibe en la plena Edad Media (que coincidiría en esencia con la dispersión del poblamiento tradicional) se haya cimentado desde etapas tempranas. La ocupación se centra ahora de forma definitiva alrededor del valle, dando plena conformación a un modelo de apropiación del medio iniciado en la Edad del Hierro y que hemos definido como paisaje cóncavo. El progresivo abandono de las tierras altas para el asentamiento y el uso intensivo del suelo se relaciona estrechamente con la constitución de un sistema campesino pleno. Sin embargo ello no implica el abandono definitivo de ese tipo de terrenos que seguirán formando parte integral del sistema productivo campesino como áreas de aprovechamiento extensivo. Por otro lado pasan a ser lugares frecuentemente sacralizados, bien sea ex novo (lo cual es más bien propio de momentos avanzados, a partir del s. XVI-XVII) o bien, muy frecuentemente, a través de la cristianización de lugares ocupados o ritualizados anteriormente. Este podría ser el caso de la ermita de San Xusto, emplazada lejos de la esfera de actividad cotidiana del campesino.

El último paso significativo en la conformación del paisaje actual de la zona se documenta en los siglos XVII-XVIII, aunque presumiblemente se haya establecido bastante antes. Como apuntamos, la Edad Media supone la práctica instauración del modelo de ocupación del medio vigente en el mundo campesino tradicional. El establecimiento de una distribución jurisdiccional basada en la parroquia recoge ese modelo a través de un reparto territorial en el que los núcleos principales de cada parroquia (las capitales parroquiales) se sitúan física y simbólicamente en el centro de los respectivos territorios.

De la confrontación entre todos estos modelos de paisaje derivan dos tipos de resultados. El primero de ellos se refiere a las diferencias que hay entre las diversas estrategias de ocupación y estructuración del entorno y a la cronología de los procesos de cambio y continuidad en el paisaje social. El segundo se refiere a la recurrencia en señalar una determinada zona del área de estudio (el Sector D) como el eje que articula los patrones de ocupación del espacio en la mayor parte de los momentos considerados.

\subsection{Cambios y continuidades en el paisaje}

Nos fijaremos primero en los puntos de inflexión más notables en sentido diacrónico. El primero se sitúa entre el Neolítico y la Edad del Bronce, con cambios significativos no tanto en el emplazamiento de los asentamientos como en las formas de señalar la presencia de éstos o de acotar áreas de especial interés: con un desplazamiento progresivo de un paisaje monumental (articulado por túmulos) a un paisaje ritual (petroglifos) y doméstico (asentamientos). Por otra parte se documenta un cambio importante en los patrones de movilidad y desplazamiento por el medio, pasándose de un patrón paralelo al río Lérez y centrado en hacer permeables las tierras altas, a otro radial, con el establecimiento de líneas de vadeo y la comunicación entre las zonas de valle y las tierras altas (Fig. 11).

Un segundo cambio de importancia se registra en el paso a la Edad del Hierro (ca. ss. VIII a.C.), intensificado al inicio de la Segunda Edad del Hierro (hacia ss. V-IV a.C.). En este caso las novedades se amplían a casi todos los niveles: asentamiento (emplazamiento y forma), formalización de la presencia humana en el entorno, conquista de tierras bajas (ya no sólo son zonas de paso sino de ocupación y explotación), formalización de límites territoriales... Como apuntamos con anterioridad, en este momento se establecen las bases de lo que, con el tiempo, será el sistema tradicional gallego de ocupación del espacio.

El tránsito al mundo medieval supone, a nuestro juicio, el último gran hito en el proceso evolutivo que venimos describiendo. El establecimiento de aldeas abiertas, la definitiva conquista de los valles, la cristianización del medio (muchas veces en estrecha relación con el universo simbólico preexistente), la formalización de las líneas de tránsito o de los límites jurisdiccionales entre comunidades, son procesos que habrían implicado, en muchos casos, amplios períodos de tiempo desde su gestación a su plasmación definitiva. En líneas generales el cambio más substancial se pue- 
de situar en época altomedieval (ca. ss. IV-V $\mathrm{V}$ d.C., Rodríguez, 1994) para ir complicándose paulatinamente y adquiriendo, en algunos casos, revestimientos novedosos o modificaciones de forma que, en esencia, no afectarán en gran medida a la conformación del paisaje hasta el siglo XIX.

En otro orden de cosas, nuestro análisis permite también extraer una lección crítica y metodológica importante: aunque se ha llamado la atención muchas veces sobre las insuficiencias del funcionalismo ecológico o el reduccionismo geográfico para explicar la configuración de los paisajes sociales, siempre conviene insistir en ello. En la zona que hemos estudiado tenemos un buen ejemplo de esas insuficiencias. Es cierto que las características del medio natural posibilitan (y lo acabamos de ver) las formas de uso del espacio y de distribución del hábitat y el poblamiento. Pero más allá de un cierto punto se agota la capacidad heurística de esas aproximaciones para comprender la organización del paisaje social. En cambio se ve cómo sobre una misma zona se establecen modelos de paisaje distintos y que suponen modificaciones drásticas entre ellos, y que, aunque mantengan en líneas generales ciertos rasgos (las formas de uso del suelo en unos casos o la organización territorial, por ejemplo), se yuxtaponen formas de paisajes muy diferentes (el ejemplo más claro es la discontinuidad existente entre el paisaje monumental y los que se siguen a partir de la Edad del Bronce).

\subsection{La articulación del territorio y la definición de un espacio sagrado}

En el momento de hacer el análisis de la geografía física de la zona comentábamos que el Sector $\mathrm{D}$ se individualiza del conjunto por razones no sólo o fundamentalmente orográficas sino sobre todo por motivos histórico-culturales.

Durante el Neolítico no se constata que la zona haya estado revestida de ningún sentido especial. Es más, parece ser un lugar ajeno a la actividad humana, pues carece de cualquier elemento de registro arqueológico. Los ejes de movimiento que articulan el conjunto de la zona siguiendo líneas paralelas al río Lérez implican que este área de Fentáns sea un lugar marginal en este momento. Cabe, no obstante, la posibilidad de que el vacío de monumentos sea precisamente indicativo de que en ese momento la zona ya era considerada como un espacio liminal entre territorios sociales distintos aunque no habría adquirido ningún carácter especial.

En la Edad del Bronce se localiza en ella uno de los conjuntos más importantes de petroglifos. El Sector D es ahora, indudablemente, un lugar que forma parte del espacio utilizado y concebido por las comunidades. En principio se podría pensar que la distribución de petroglifos en el Sector $D$ responde a las condiciones normales de emplazamiento de esos elementos y que su presencia debe entenderse en relación con el control de reservas de pasto (brañas, humedales, cuencas) y el control de líneas de tránsito a través del terreno y entre zonas ecológicas distintas (de hecho todo el espectro de Unidades que hemos identificado: 1 , 2, 3, 4 y 5, aparecen interconectadas en este Sector D). Sin embargo parece haber diferencias entre la concentración de grabados en este Sector D y las restantes concentraciones masivas de la zona: es especialmente'variada y densa, con motivos muy poco frecuentes como las armas; no parece dar acceso a ninguna zona de asentamiento; se enfrenta con la única concentración importante de grabados de la margen Sur del Lérez (Lombo da Costa) que, además, sigue unos patrones de emplazamiento muy semejantes (Fig. 9); la línea imaginaria que une ambos grupos representa el límite oriental para la distribución de los petroglifos en esta zona (salvo grabados aislados), al tiempo que supone el límite de la zona vadeable del Lérez y el propio límite visual del Sector A, esto es, el punto extremo del valle medio del Lérez; no se han localizado evidencias de asentamientos de la época, a pesar de haber aplicado, en la medida de lo posible, la estrategia de investigación oportuna (prospección intensiva aprovechando los puntos en los que la apertura de pistas, roturaciones forestales y de terrenos removidos por el ganado permitía examinar el subsuelo).

Teniendo en cuenta las correspondencias formales que hemos apuntado entre formas de paisajes arqueológicos, así como las características morfológicas de la zona y la significativa ausencia de yacimientos de ciertos tipos y épocas, se podría formular ahora una hipótesis complementaria. Podríamos proponer que la presencia (o ausencia) de elementos arqueológicos se corresponde no sólo con patrones de aprovechamiento económico del medio, sino más bien con la existencia de un espacio ocupado simbólicamente (y no sólo funcionalmente).

¿Qué tipo de contenido simbólico pudo alber- 
gar? La extraordinaria densidad de petroglifos existentes en ese Sector (rasgo visible si se contempla desde una perspectiva comarcal y en interrelación con la distribución de petroglifos de las tierras de Campo Lameiro y Cotobade: concretamente se han identificado 90 piedras con grabados en una superficie de $2 \mathrm{~km}^{2}$ ), unida al hecho de que entre ellos se encuentren algunos de los ejemplares más ricos y complejos del arte rupestre gallego (Laxe das Ferraduras, Chan da Lagoa, puñales de Campo de Matabois...), puede ayudarnos a descodificarlo. Igualmente, el hecho de que esos petroglifos se distribuyan definiendo una línea de paso que tiene una longitud total de casi $3 \mathrm{~km}$., que se inicia y termina con petroglifos complejos (Laxe das Ferraduras y puñales de Campo de Matabois respectivamente), y que en sus zonas de umbral o de límite importante encuentra a otras rocas igualmente complejas (Chan da Lagoa, Outeiro de Pan Trigo), podría entenderse de este mismo modo. Asimismo, el hecho de que esa línea empiece y acabe en petroglifos con representaciones de armas, que son en general relativamente excepcionales en Galicia. En definitiva, todo ello permite proponer como hipótesis más verosímil (al menos por el momento) que se trata de un lugar de prestigio sagrado, construido sobre un espacio silvestre, significativo por la función liminal, de umbral entre zonas distintas y de jalón natural (recordemos que hacia el Este la densidad de petroglifos (Fig. 9) decrece notablemente hasta casi desaparecer), que fue un área respetada y sacralizada desde la Edad del Bronce.

En la Edad del Hierro la zona mantiene rasgos de individualización. La distribución de castros acentúa la dualidad entre las tierras al Oeste y el vacío casi absoluto al Este (sólo un ejemplo dudoso). Además de esta posición físicamente liminal, la línea de divisoria de ese Sector D constituye el límite que cierra visualmente las tierras de valle al Oeste, la primera y más perceptible línea de horizonte que se observa desde todas las tierras bajas $\mathrm{y}$, en especial, desde todos los castros. Precisamente sobre esta divisoria y línea de horizonte percibida es donde se asientan las dos inscripciones indígeno-romanas. Obviamente esta distribución desigual del poblamiento castreño está condicionada por un entorno físico desigual; lo que el Sector D y los símbolos en él dispuestos representan es la separación entre ambas zonas, la formalización y el reconocimiento de esa diferencia; esto es, la previsible conformación de un reparto terri- torial. Recordemos, además, que en la otra orilla del río y alineada casi perfectamente con esta zona se encuentra la ermita de San Xusto, cuyo origen prerromano es, por el momento, imposible de demostrar pero, al menos, no sería en absoluto incoherente con nuestra propuesta.

Es posible, por lo tanto, que tengamos aquí el testimonio arqueológico de la presencia de unidades sociales supralocales cuya existencia en el mundo castreño del noroeste peninsular y permanencia durante época romana ha sido definida por los historiadores de la antigüedad (Brañas, 1995; Pena, 1991-3). El espacio de frontera, que coincide con un accidente orográfico prominente, con una divisoria o montaña que se individualiza de forma ostensible sobre su entorno, adquiere un carácter simbólico especial a través de los elementos arqueológicos que lo monumentalizan. Parece haber constituido desde la Edad del Bronce y en la Edad del Hierro un espacio sagrado que, de algún modo, se relacionaba con el movimiento y la peregrinación: frontera, montaña y camino son entonces los atributos arqueológicos reconocibles de una geografía mítica que, según lo que sabemos de las mitologías celtas e indoeuropeas (que son el referente básico para el momento crono-cultural que nos ocupa), identificaba con esos elementos el tránsito al más allá (García, 1990).

Con la cristianización y el paso a la Edad Media el significado y contenido de esta zona cambian, pero permanece el hecho de ser un lugar especialmente señalado, tal vez en un sentido bastante semejante al que lo había sido en la Edad del Hierro. Posiblemente en un momento indeterminado de la Edad de Media, y con toda certeza plenamente en vigor en el siglo XVII, este papel liminal se formaliza en el establecimiento de unos límites parroquiales que, obviando localmente la línea impuesta por el curso del Lérez, ascienden por la divisoria del Sector D (en coincidencia exacta con el emplazamiento de las inscripciones) para integrar el área de Fentáns en la parroquia de San Xurxo de Sacos, al Sur del Lérez. La significación de este límite se refuerza por su coincidencia con el de otra entidad territorial a mayor escala como son los arciprestazgos, actuando de nuevc el Sector D como punto de separación de los dt Montes, Moraña y Cotobade. Por fin el repartc municipal en el siglo XIX recoge también esta di ferencia, marcando en la zona la separación entri Campo Lameiro y Cotobade.

La propia distribución del resto de las parro 
quias supone una nueva forma de reconocer la especificidad del lugar, ya que todas la parroquias cercanas al norte del Lérez se disponen radialmente en torno al Sector D, incorporando las líneas de tránsito que marcan el ascenso desde el río hasta las zonas altas y en las que se localizan las mayores concentraciones de petroglifos. La distribución parroquial ofrece, pues, una especie de síntesis de los dos modelos de preeminencia del Sector D: como límite estático (a partir de la Edad del Hierro) y como línea de movimiento específica dentro de un vasto conjunto de ellas (Edad del Bronce).

Corolario. Hemos descrito en líneas generales los modelos de paisaje que se suceden en una determinada zona a lo largo de casi 5000 años. Hemos observado más en concreto cómo se configura en cada uno de esos momentos el espacio social y económico y cómo se articula sobre éste el territorio político. Hemos entrevisto incluso que esa articulación se construye sobre un paisaje sagrado. Pero aquí debemos acabar. Stop making sense. Se podría seguir acumulando interpretaciones para justificar los fenómenos entrevistos. Pero de ese modo nos moveríamos inconsciente e inconsistentemente de la mera constatación de un fenómeno que debió tener algún sentido, y de la intuición inicial de ese sentido, a la producción de sentidos emanados directamente de nuestra subjetividad y que con total seguridad no tendrían nada que ver con las subjetividades que debemos analizar. La espiral hermenéutica se podría extender tanto como quisiéramos. Pero debemos abandonarla en el punto mismo en el que los datos, la materialidad que de ellos se desprende y las valoraciones provisionales que anticipamos, permiten percibir un algo que queda para siempre más allá de las posibilidades de nuestra interpretación.

En cambio creemos que este trabajo muestra que el análisis de las evidencias geográficas y arqueológicas de la zona, su descripción y comparación y la adopción de una estrategia deconstructiva no sólo nos permite reconocer los modelos de organización espacial de cada momento, sino que también nos sitúa en condiciones de comprender más adecuadamente la formación del paisaje tradicional como resultado de un amplio proceso histórico. Así las cosas, el hecho de una distribución parroquial y municipal en principio extraña, especialmente en lo que se refiere al área de Fentáns y a la circunstancia de que el límite entre los municipios de Campo Lameiro y Cotobade no se ajuste en ese punto al límite "natural" que establece el río Lérez, sino que se desplace sobre éste, no sólo empieza a resultar más comprensible, sino que además se convierte en sí mismo en un documento arqueológico que permite acceder a un registro empírico que, de otro modo, permanecería para siempre ajeno al estudio histórico.

El paisaje, como toda realidad humana, refiere una amplia pluralidad de códigos significativos y, como tal, puede ser leído desde todos ellos. En este trabajo hemos procurado desvelar esa multiplicidad aproximándonos finalmente a una dimensión sagrada que lógicamente no anula la posibilidad de que ese espacio haya sido simultáneamente el soporte de otras funcionalidades. Así este trabajo contribuye igualmente a la definición de una metodología para la identificación y análisis de este tipo de espacios. Finalmente creemos que también sienta las bases para replantear el estudio de los ejémplos de cristianización de lugares arqueológicos; tradicionalmente se han interpretado estos casos como una ruptura cultural (entre el nuevo orden cristiano y el anterior) y en un sentido 'pedagógico' (recurso para convertir al vulgo); pero desde la perspectiva que abren las consideraciones anteriores habría que tomarlos más bien como ejemplos de incorporación de tradiciones y creencias anteriores por parte del nuevo orden socio-ideológico en construcción a través del cristianismo. La correcta comprensión del fenómeno pasa una vez más por valorar la permanencia y no sólo la discontinuidad.

\section{BIBLIOGRAFÍA}

Álvarez NúÑEZ, A. (1979): "Nuevas insculturas en Campo Lameiro". Gallaecia, 5: 17-72.

- (1986): Castro de Penalba. Campaña de 1983. Arqueoloxía/Memorias, 4. Dirección Xeral do Patrimonio Histórico, Consellería de Cultura. Santiago.

Bradley, R.; Criado Boado, F. y Fábregas Valcarce, R. (1994a): "Rock art research as landscape archaeology: a pilot study in Galicia, northwest Spain". World Archaeology, 25 (3): 374-90.

- (1994b): "Los petroglifos como forma de apropiación del espacio: algunos ejemplos gallegos". Trabajos de Prehistoria, 51 (2): 159-68.

- (1995): "Rock Art and the prehistoric landscape of Galicia: the results of field survey between 1992 and 1994". Proceedings of the Prehistoric Society, 61: 347-370.

BRAÑAS, R. (1995): Indíxenas e romanos na Galicia céltica. Follas Novas. Santiago de Compostela. 
Cobas Rodríguez, I. y Prieto Martínez, P. (e.p.): "Patrones de regularidad formal en la cerámica de la Edad del Bronce y del Hierro en Galicia". Gallaecia, 13.

Criado Boado, F. (1989): "Arqueología del Paisaje y Espacio Megalítico en Galicia". Arqueología Espacial, 13: 61-117.

- (1991): "Del poblamiento pretérito a los paisajes arqueológicos". En F. Criado (dir.) et alii: Arqueología del Paisaje. El área Bocelo-Furelos entre los tiempos paleolíticos y los medievales. Arqueoloxía/Investigación, 6. Dirección Xeral do Patrimonio Histórico, Consellería de Cultura. Santiago: 245-55.

- (dir.) (e.p.): Memorias del Espacio. La culturización del espacio en la Prehistoria. Monografías de Arqueología del Paisaje 1. Universidad de Santiago de Compostela. Santiago.

Criado Boado, F. (dir.), Bonilla Rodríguez, A., Cerqueiro Landín, D., Díaz VÁzquez, M., GonzÁlez MéndeZ, M., Infante Roura, F., Méndez Fernández, F., Penedo Romero, R., Rodríguez Puentes, E. y Vaquero LAstres, J. (1991): Arqueología del Paisaje. El área Bocelo-Furelos entre los tiempos paleolíticos y los medievales. Arqueoloxía/Investigación, 6. Dirección Xeral do Patrimonio Histórico, Consellería de Cultura. Santiago.

Criado Boado, F. y Parcero Oubiña, C. (e.p.): "Arqueología de las formas de parcelación del espacio en la prehistoria de Galicia". Actas del Congreso Paleoambiente Cuaternario na Península Ibérica (Santiago, 1995).

Criado Boado, F.; Parcero Oubiña, C. y Villoch VázQUEZ, V. (1995): "Control Arqueológico del Oleoducto Coruña-Vigo. Fase II: Seguimiento de las obras de construcción". Actas del XXI Congreso Nacional de Arqueología, I (Vigo, 1993): 309-16. Vigo.

Criado Boado, F.; Villoch Vázquez, V.; Prieto MartíNEZ, P.; GonzÁlez MÉndez, M. (e.p.): "Yacimientos habitacionales de constructores de Túmulos: aproximación a una problemática". Actas del Congreso $O$ Neolítico Atlántico e as Orixes do Megalitismo (Santiago, 1996).

DERRIDA, J. (1989): La deconstrucción en las fronteras de la filosofía. Paidós. Barcelona.

Ferreira Priegue, E. (1988): Los caminos medievales de Galicia. Boletín Auriense, Anexo 9. Museo Provincial. Ourense.

Feyerabend, P. (1974): Contra el método. Esquema de una teoría anarquista del conocimiento. Ariel. Madrid.

Foucault, M. (1976): Historia de la locura en la época clásica. Fondo de Cultura Económica. México.
Fuentes Fuentes, J.L. (1976): "La romería de San Xusto en San Xurxo de Sacos (Pontevedra)". Gallaecia, 2: 245-72.

García Alén, A. y Peña Santos, A. de la (1980): Grabados rupestres de la provincia de Pontevedra. Fundación Barrié de la Maza. A Coruña.

GarCía FernándeZ-Albalat, B. (1990): Guerra y religión en la Gallaecia y Lusitania antiguas. Ediciós do Castro. Sada, Coruña.

Hoyo, Cardenal Jerónimo del (1950): Memorias del Arzobispado de Santiago. (edición de A. Rodríguez González y B. Varela Jácome). Porto y Cía. Editores. Santiago de Compostela.

JoHnsen, H. y Olsen, B. (1992): "Hermeneutics and Archaeology: on the philosophy of Contextual Archaeology". American Antiquity, 57 (3): 419-36.

Méndez Fernández, F. (1994): "La domesticación del paisaje durante la Edad del Bronce gallego". Trabajos de Prehistoria, 51 (1): 77-94.

Méndez Fernández, F.; González Méndez, M. y Amado Reino, J. (1995): "Control Arqueológico del Oleoducto Coruña-Vigo. Fase I: Trabajos Previos y Superficiales". Actas del XXI Congreso Nacional de Arqueología I (Vigo, 1993): 293-296. Vigo.

PARCERo OubiÑA, C. (1995): "Elementos para el estudio de los paisajes castreños del Noroeste Peninsular". Trabajos de Prehistoria, 52 (1): 127-144.

Pena Graña, A. (1991-3): Narón. Un concello con Historia de seu (I y II). Concello de Narón. Narón, Coruña.

Peña Santos, A. de la (1990-1): "Consideraciones sobre las vías romanas de la provincia de Pontevedra". Castrelos, 3-4: 217-43.

Peña Santos, A. DE la; Costas Goberna, F.J. y Rey GarCíA, M. (1993): El arte rupestre en Campo Lameiro. Folleto-guía publicado por la Consellería da Presidencia e Administración Pública de la Xunta de Galicia.

Rodríguez Colmenero, A. (1993): Corpus-catálogo de inscripciones rupestres de época romana del cuadrante Noroeste de la Península Ibérica. Larouco, anejo 1. Sada, Coruña.

Rodríguez FERnÁNDEZ, T. (1994): "El fin del mundo fortificado y la aparición de las aldeas abiertas. La evidencia del Centro-Oriente de Lugo (Samos y Sarria)". Espacio, Tiempo y Forma, I (7): 153-89.

VILLOCH VÁzQUEZ, V. (1995): "Monumentos y petroglifos: la construcción del espacio en las sociedades constructoras de túmulos del Noroeste peninsular". Trabajos de Prehistoriam 52 (1): 39-56. 